Two Pillars of Institutions: Constitutive Rules and Participation

\title{
Wolfgang Huemer
}

1. Constitutive Rules: An Intellectualistic Bias?

Rules do more than just limit our freedom and restrict our room for manoeuvre in everyday life. The recent debate, especially in social ontology, has paid more and more attention to the fact that there are rules that can initiate new forms of behaviour and create institutions and new social realities. ${ }^{1}$ The conception of constitutive rules that is operative in this debate arguably has a strong intellectualistic bias, though, which, in my point of view, is the result of a one-sided diet of examples. Very often, the focus is on complex and highly regulated institutions like universities, money exchange, or private property. Some philosophers prefer to illustrate the role of constitutive rules with the example of games - and then focus on chess and other highly abstract games that one can learn to play, at least at a basic level, by simply getting familiar with a handful of explicitly stated rules. ${ }^{2}$

To overcome this bias and get a more equilibrated understanding of constitutive rules, we should nourish our thinking with a richer choice of examples. Consider institutions like the Wiener Kaffeehaus or the Italian bar. Prima facie, the two institutions serve the same

\footnotetext{
${ }^{1}$ This point was introduced to the contemporary debate by John Rawls (1955) and John Searle (Searle 1969). It is sometimes attributed to Kant (cf., for example, Glock 2000), who does distinguish between constitutive and regulative rules. It is a question of exegesis that goes well beyond the scope of this paper, however, whether and, if so, to what extent the contemporary distinction between constitutive and regulative rules is already operative in Kant.

${ }^{2}$ I am oversimplifying here to echo a widespread view. Of course, learning to play chess consists in much more than becoming familiar with rules like the "Laws of Chess" of F.I.D.E., the world chess federation, which formulates the essential rules of the game in five articles. This booklet makes sense only to a person who already knows what games are and what purpose they serve - for these aspects are not specified in the rulebook. She has, in other words, to be familiar with the practice of playing competitive games in order to know what to do with the rulebook. I discuss this point in more detail in Huemer (2020).
} 
purpose: they are places where you can get a cup of coffee in a pleasant environment. Both institutions have long traditions and there are clear, yet unwritten rules that visitors are expected to respect in order to behave in manners that are considered appropriate in the respective places. Some of the rules could, of course, be stated explicitly. Think, for example, of the ones that govern economic exchange specific for this kind of institutions. An explicit law determines, for example, how much sales tax the owner of the place has to charge. An unwritten rule suggests that once you have ordered a drink, you have to pay for it, even if for some emergency you have to leave the place before drinking it. If you confront your experience in a Wiener Kaffeehaus with that in an Italian bar you easily realize, however, that there are many more tacit rules that guide the behaviour of waiters and customers and determine the atmosphere in the respective places - some of which might vary from one region to another or apply only for a specific kind of bar or Kaffeehaus. It would be extremely difficult, if not impossible, to spell out this fine web of rules in an explicit manner.

A similar point can be made about games: learning to play a game typically requires more than becoming familiar with explicitly formulated rules. When you learn to play football or tennis, you will first have to acquire certain skills and work on your physical abilities and your technique that are necessary to make a move in the game. You cannot just "calculate" the move on the basis of the rules, as it were, you have to learn to perform the moves in a "real-world" scenario. ${ }^{3}$ Physical training and acquisition of the rules that govern the game normally go hand in hand. Novices are typically first made familiar with the equipment that is needed to play the game (the racket, the balls, the apparel, etc.) and the specifics of the locations where it is played (the size of the court, the lines, the net, etc.) - and at the same time they are shown how to make the most basic moves in the game. Their trainer explains

\footnotetext{
${ }^{3}$ I am following here a suggestion that was made by Jaroslav Peregrin, who suggests that the rules of language like that of football - are "co-delimited by the physical laws of the real world" $(2014,35)$.
} 
them, to stick with our example, where to position themselves on the court, how to hold the racket, and how to hit the ball with it. Thus, learning to recognize the phenomena that are relevant in the game and to make moves go hand in hand. Moreover, by acquiring these skills, one also learns to distinguish moves that are legitimate in the game from those that are not. ${ }^{4}$ With time, the novice will improve and learn to make more demanding moves in the game and, at the same time, improve her skills to recognize the phenomena that are relevant in the game.

This short discussion of "non-standard" examples shows two points that seem relevant to me: first, many of the rules that are constitutive of institutions or forms of behaviour are tacit and have never been fully spelled out; they are typically enacted before or independently of their being explicitly formulated. Second, if we want to do justice to the complexity of our shared social reality, we need to widen our perspective. The focus on constitutive rules is too narrow, we also need to pay attention to the skills and the participant's shared commitments that are required to engage in the relevant practices. Both points stand in contrast to the received view on constitutive rules, which takes it for granted that constitutive rules presuppose linguistic or some other form of symbolic representation.

In the present chapter I pursue two related goals: I will sketch the received view and bring out its intellectualist bias and, at the same time, argue for a richer understanding of constitution and point out that our dynamic social practices require a form of shared commitment and require all participants to stay in tune with one another. I will characterize the intellectualist bias with the example of three assumptions, in which it becomes particularly evident and according to which (i) constitutive rules have a logical form (Section 2), (ii) constitutive rules do not have normative force (Section 3) and (iii) rules are essentially tied to a sanctioning

\footnotetext{
${ }^{4}$ In this point, I am following John Haugeland, who has insisted in the relevance of skills and commitment for our understanding of constitution. I will come back to this point below.
} 
authority (Section 5). My strategy will be to contrast these assumptions with real life examples, which unveil them as prejudices and show the need for a wider conception of constitution. In the more constructive parts of the chapter I will discuss two elements on which such a conception would need to be based. I will argue that we need to distinguish between criteria for the correctness of a move and criteria for participation in the game in order to get a better understanding of the shared commitment to the practice that is demanded from the participants (Section 4). The switch of perspective from rules to participation will allow me, in the final Section, to draw attention to the fact that continued participation in a dynamic and complex social practice requires the members of a community to stay in tune with one another, which is possible only if they continuously calibrate their own behaviour to that of the other participants.

\section{A Prejudice In Favour Of Explicit Rules}

When John Searle introduced the distinction between regulative and constitutive rules, he did so by pointing out that there is a difference in logical form: while regulative rules have the form "Do $X$ " or "If $Y$, do $X$ ", constitutive rules have the form " $X$ counts as $Y$ in context $C$ " $(1969,35 \mathrm{ff}) .{ }^{5}$ Moreover, Searle has argued that constitutive rules require language. They attribute the social role $Y$ to $X$ not on the basis of a natural prelinguistic feature of $X$. Rather, "the status function specified by the Y term can be fulfilled only if it is recognized, accepted, acknowledged or otherwise believed in" (Searle 1995, 62). Constitutive rules, thus, require a

\footnotetext{
${ }^{5}$ Searle has taken up this logical form in many of his later publications. The logical form of constitutive rules has been analyzed in different ways, for example, by Randall (1971), Glüer and Pagin (1998) and Hindricks (2009). For my purposes, the exact logical form is not relevant. However, I find it remarkable that there are discussions about logical form in the first place, as this demonstrates that the underlying assumption, according to which each constitutive rule can, in principle, be spelled out explicitly, is widely shared.
} 
system of symbols that can represent the status function properly. "So we have to have words or other symbolic means to perform the shift from the X to the Y status" (Searle 1995, 70). According to this view, constitutive rules are - or can easily be - explicitly formulated. Moreover, it entails that language is not among the social institutions that are created by constitutive rules, for that would lead to a vicious circularity. ${ }^{6}$ From here it is but a small step to argue that constitutive rules - explicit rules or rules that can easily be spelled out explicitly - are logically prior to the institutions they create.

Let us take a look at two examples that might cast some doubt on this perspective. The examples that I want to consider show that rules of the form described are results of ex-post rational reconstructions (that is, of fictionalizing accounts) of what has actually happened when a social institution came into existence. This holds even for institutions that are among the paradigmatic examples for the intellectualistic understanding of constitutive rules. The first example that I want to submit to your attention is the Alma Mater Studiorum - University of Bologna, which is often considered the world's oldest university. In fact, if you walk through Bologna's historical centre, you will see that the number " 1088 " is proudly exhibited on many buildings, all of which belong to the university. 1088 - the year in which the university presumably was founded. Sober historians are more hesitant, however, for there never was, as far as we know, a ribbon-cutting ceremony, nor do we have any official document that dates back to 1088 and would qualify as by-laws, statute, or mission statement of this institution. The first official document that would qualify in this sense is the Authentica Habita proclaimed by Federico Barbarossa in 1158, some 70 years later.

\footnotetext{
${ }^{6}$ This point was famously made by Wittgenstein (2009) and, in a more explicit manner, by Sellars (1991, 321). While some take this to imply that there must be implicit constitutive rules that do not require language, Searle argues that it shows that language is not constituted by rules - which confirms the old saying that one philosopher's modus ponens is another philosopher's modus tollens.
} 
What happened in 1088 that could have brought this important institution into existence? At the time, Bologna already had a standing tradition of courses in law, theology, and philosophy that were popular and attracted students from all over Europe. In or around the year 1088, however, a qualitative step in the development took place - though it is not possible to date the exact year. ${ }^{7}$ A committee of historians under the guidance of the poet Giosuè Carducci, which was operative in the mid-1880s, established 1088 as the date of the foundation of the Alma Mater Studiorum with reference to a document that affirmed that in that year a certain Irnerius and a certain Pepo started to teach law in Bologna - and just in time to organize a big centenary celebration in 1888 . In a booklet that had appeared some hundred years later, at the occasion of the nineth centenary, the dating of the foundation of the University was justified with the fact that "in that year, there appeared free arrangements for the teaching of law which were independent of the religious schools of Bologna" (Rüegg 2003, 5). All the historical evidence seems to confirm, thus, that the University of Bologna has not been founded in one single moment; its coming into existence was rather one step in many of a continuous and complex process of development. Historians engage in ex post discussions where they exchange arguments with the scope of individuating one precise step that was particularly significant and use it to date the foundation of the university. We see that there is some arbitrariness in the dating. Most importantly, it is very unlikely that the persons that were actually involved in this process did perceive that very moment as special in any sense; very probably they would not have identified it as the moment in which a new institution was created.

\footnotetext{
${ }^{7}$ For a discussion of the historical facts concerning the foundation of the University of Bologna and historiographic problems connected to them, cf. Rüegg (2003, $4 \mathrm{ff})$. One can find some information on the official website of the University (https://www.unibo.it/en/university/who-we-are/our-history/university-from12th-to-20th-century, consulted on July 17, 2020).
} 
A similar story can be told about chess or football. Both games are far too complex to have been invented by one individual person in one specific moment in time. Rather, they have evolved from similar games ("proto-chess") over a long period in which the rules were passed on from one player to the other - very likely by being enacted on a chess board or on a field. When, in a later moment, the rulebooks of chess and football were formulated, they merely put down the rules that were already in place.

The historical facts that I have just sketched illustrate that the stipulation of a system of constitutive rules does not need to have temporal priority over the social practices or institution they bring about. There can be - and there actually have been many -cases where new forms of behaviour and institutions have come into existence without there being a codified set of constitutive rules - and it is important to note that this holds also for very complex and stable institutions like universities or games like chess. But does the temporal order reflect the logical one? The examples I have presented show that the new practices have grown out of old ones in an organic and continuous manner that was not, as far as we know, designed or piloted by any of its members. A sufficiently large or influential group of members of the community started to apply the already existing rules in a new way and to exhibit new forms of behaviour that showed recognizable regularities. With the time, these forms of behaviour sedimented in the community and, thus, established a new standard with which community members then were supposed to conform if they wanted to partake in the practice. Put in a slogan, we could state that it is not the rule that stipulates a practice, it is the practice that stipulates a rule.

This does not hold for all cases, though, and of course there are institutions and forms of behaviour that come into existence by explicit stipulation of the constitutive rules - new games are invented, new competitions initiated, new universities founded, etc. However, these acts of foundation of a new institution or new forms of behaviour typically take place within a 
larger framework of already existing practices and rules, some - but by far not all - of which are already codified, like legal regulations. Moreover, stipulations of new practices are successful only if other members of the community go along and are willing to conform their own behaviour to the new standards. ${ }^{8}$ Finally, we should not underestimate the importance of law- and rulebooks. Once the rules are pinned down, they serve as a point of reference that makes the system become more stable and immune against changes. My point was not to undermine the relevance of explicitly formulated rules; I merely wanted to show that systems of explicit rules are not logically prior to the institutions they constitute.

\section{A Prejudice Against Normative Force}

According to a widely held assumption, which is also characteristic for the received view, constitutive rules do not have normative force and, in consequence, cannot be violated. The underlying idea is that constitutive rules determine what does and what does not count as a move in a game. They allow us, in other words, to distinguish forms of behaviour that are moves in a game or pertain to a certain practice from other forms of behaviour that are not. If, for example, a person in front of a chess board moves her bishop diagonally on the board, waits until her opponent has made a move and then moves the tower ahead in a straight line, her behaviour does conform to the rules. She is, thus, playing chess. Had she moved the tower diagonally, made two moves in a row without giving her opponent the time to make a move, or scattered the opponent's pieces off the board, her behaviour would not qualify as moves in a chess game. The point might also be expressed in a different way - which assimilates the

\footnotetext{
${ }^{8}$ For an interesting account of rules that takes the mechanisms of acceptance in a wider community into account and discusses strategies that are helpful in propagating new rules in a aocial community, cf. Bicchieri (2006; 2017).
} 
rules of chess to a descriptivist understanding of the rules of grammar - by stating that the former are mere descriptions of the regularities that become manifest in the behaviour of persons in relevant situation (i.e., persons in front of a chess board). Not everyone who comes to sit in front of a chess board knows or intends to play, however, and so the statement would have to be qualified, restricting it to the behaviour of those who actively participate in the practice. Circularity looms - at least as long as participation in the game is explained on the basis of constitutive rules. I will discuss this point below.

According to the received view, thus, a person, who does not conform to the rules, does not play chess. Should someone behave like the renitent chess player in our example above, her moves can be qualified as incorrect in relation to the rules of chess. According to an influential argument, the use of the terms "correct" and "incorrect" in these contexts is descriptive, though, and does not have normative force. They merely describe the use of a word in a linguistic community, "but they cannot be said to guide speakers in ordinary linguistic usage" (Glüer and Pagin 1998, 224) and in consequence do not imply any moral obligation to behave in a certain way. Along similar lines, Anandi Hattiangadi has argued that constitutive rules are hypothetical, not categorical rules. With regard to the rules that constitute meaning, she suggested that they should be reconstructed in the following way: "If I want to be understood by others, I better use my words as they do" (Hattiangadi 2006, 234). Thus, if you want to make yourself understood, you better use the term "horse" - and not, say, "cow", when talking about horses. Applied to the game of chess, we could state: if you want to play chess, you better conform your behaviour to the rules and move the pieces accordingly. Should a person make an incorrect move according to the rules of chess, her behaviour would not count as "playing chess"; she has rather come to play a different game, call it "shmess", that is constituted by different rules and has only superficial similarities with chess. 
There is something that does not quite convince in this descriptivist reading of "correct". It does not leave sufficient space for bad or unskilled chess players. Not all amateurs reach the level of tournament: I, for one, like to play chess every once in a while, but - I hate to admit it - I play it really badly. Occasionally it happens that I commit an error, sometimes without even noticing. I clearly remember that one day I found myself in the middle of a game realizing that both of my bishops were on a white field. Clearly, I must have made a bad move earlier in the game with the bishop that is supposed to move only diagonally on black fields and my opponent was polite or distracted enough not to point out my faux pas. Nonetheless, if someone had asked me what I had been doing, I would have told her that I had been playing chess. A mistake, every once in a while, does not change the game, it just unveils that you're a bad player.

The descriptivist conception of constitutive rules, according to which the rules that constitute a game cannot be violated, might - again - be the result of a one-sided diet of examples. In chess it seems particularly easy do distinguish legal moves from moves that are not. Moreover, any player who spots an illegal move from her opponent will immediately protest and insist that the move is undone, or else quit the game. In other games, violations are much more difficult to discern and sometimes even tacitly accepted. While it is easy to see whether the bishop is on a black or on a white field, it is often much more difficult to decide whether a certain formation in a football game qualifies as an offside or whether an encounter of two players counts as a foul. In the case of football, intentional fouls, i.e., intentional violations of the rules that provide a relevant advantage, are quite common and often even expected by the teammates, the manager, and the fans of the team. Occasionally, outfield players even violate the most basic rule of the game and intentionally touch the ball with their hands. This is what happened, for example, in the quarter finals of the world championship in 2010, where Uruguay met Ghana. The match was tied when, deep in the extra time, Uruguay's Luis Suárez 
handballed on the goal line, denying Ghana an almost certain winning goal. The Ghanaian player Asamoah Gyan missed the penalty, Uruguay won the penalty shootout that followed and advanced to the semi-finals of the tournament, where they lost 2:3 against the Netherlands. Suárez had clearly violated a rule that is constitutive of the game - and was suspended from the game with a red card. If constitutive rules had no normative force, we would have to conclude that Suárez and his team did not play football, but a different game ("shmootball") that only had superficial similarities with the former. This seems implausible, though, as the match was part of the world championship and Suárez's move was instrumental for his team to reach the semi-finals. It seems more natural to me to suggest that Suárez's behaviour counts as a move within the game, if an illegitimate one. This reading of Suárez's behaviour indicates that constitutive rules do, in fact, have normative force and guide the behaviour of those who participate in the practice.

A defender of the anti-normativist view might resist this reading, arguing that behaviours like the one exhibited by the unskilled chess amateur or the overly ambitious professional footballer disqualify them in an important sense from participation in the game. Both do make moves on a chessboard or a football field, respectively, but the very fact that they do not conform their behaviour to the rules that are constitutive of the game unveils that "in reality" they are not playing that game any longer. While the amateur chess player might simply be victim of self-deception, the case of Suárez might be a more serious misdemeanour; after all, his handball was instrumental for his team to win the game and advance to the semi-finals. According to this view, Suárez's behaviour was reprehensible not because it violated a rule that is constitutive of football, but rather because he deceived the other players, the referee and the audience. Suárez fault, thus, would consist in manipulating the result of the game "from the outside". It could be argued that he managed to enforce on all persons involved in the match to accept that his actions, which were not part of the game, came to have a decisive 
impact on the result of the match. This possible reply does not seem overly plausible. To illustrate its limits, we need to reflect on the criteria for participation in a game.

\section{Rules, Participation, Commitment}

So the question remains: did the unskilled chess amateur and the unfair football player make a mistake in the game or did they start to play a different game? How can we resolve the question? In order to get a clearer view, it is probably best to reconsider the roles of constitutive rules in the descriptivist conception, on which the anti-normativist argument is based. This conception, it seems to me, has a regulist leaning ${ }^{9}$, which makes it particularly apt to account for the approach philologists take towards dead languages or for the attitude of a student of a foreign language at the beginner's level.

For the philologist, who studies a dead language at an abstract level, but never uses it to express herself or to interact with other members of a linguistic community, it seems reasonable to consider language as a formal system of symbols that can be described by a set of abstract rules. Language students at the beginner's level, on the other hand, often rely on hypothetical rules like the ones discussed above ("If you want to make yourself understood in Italian, you better use the term 'cavallo' when talking about horses"). Both the philologist and the language student are familiar with the rules, but do not apply them; they do not genuinely use the languages they study, but rather treat them as a formal game where they make abstract

\footnotetext{
${ }^{9}$ Robert Brandom distinguishes between two conceptions of rules he takes untenable and that constitute the Scylla and Charybdis between which a middle way is to be found: regulism and regularism. The former is the view "that properties of practice are always and everywhere to be conceived as expressions of the bindingness of underlying principles", while the latter suggests that "practices should be understood just as regularities of behaviour" (cf. Brandom 1998, 18ff.).
} 
moves. ${ }^{10}$ They do not participate in the language game; they merely study the moves that can be made in the game "from the outside", as it were. Moreover, they need to rely on their competence in their first languages to conduct these studies; the languages in which the rules of grammar of the foreign language are formulated and which they do use to express themselves and to interact with other competent members of their linguistic community.

These considerations suggest that in order to get a better understanding of the normative force of constitutive rules, we need to distinguish between the criteria that determine the correctness of a move in the game, on the one hand, and criteria for participation in the game, on the other. With regard to the former, anti-normativists could argue that they merely determine, in a descriptive manner, what counts as a legitimate move in a game in a specific social community - and, at best, make space for hypothetical commitments, i.e. commitments that are contingent on the desire to make a correct move in the language game. I will not discuss this claim at this point and limit myself to point out that this project seems particularly promising when analysing games that are played in clearly defined situations and consist in moves that can easily be discerned - like chess. When it comes to more "messy" practices or institutions, the project will become more difficult, if not impossible, to carry out. In the case of natural languages, we have complex systems that are continuously changing and vary considerably between regions, social contexts, and even from one individual to another. Moreover, the rules of grammar typically allow for a high number of exceptions, which suggests that they are better thought of not as explicit rules that determine all moves in the game - they are rather guidelines for persons who are not native speakers or in occasional cases of doubts.

\footnotetext{
${ }^{10}$ Both can, of course, become participants - once they start to use the foreign language to express themselves and to interact with others. This would require them to take a different attitude towards the rules: rather than treating them as an object of study, they would need to interiorize them and start to engage in genuine rulefollowing behaviour.
} 
The criteria for participation in the game are more difficult to spell out and require us to appreciate John Haugeland's suggestion, according to which constitution is not only about rules, but comprises also know-how and skills as well as a form of commitment (cf. Haugeland 1998). To participate in a game, familiarity with a set of explicitly formulated principles is neither necessary nor sufficient, nor can participation be reduced to one's making the correct moves. Not only would this characterization risk circularity ${ }^{11}$, it would also fail to take the distinction between following a rule and acting in accordance with it into account.

In order to qualify as a participant of a practice, one has to follow the relevant rules which, in turn, requires one to have the know-how or skills necessary to make a move in the game. If we consider games like chess, football, or tennis, it is easy to see that two sets of skills are required: for one, it is necessary to possess the relevant capacities to recognize whether the phenomena in the game are in accord with the standards and the rules that constitute it. To possess this kind of skill means to be able to distinguish legal moves from those that are not. Examples like football or tennis show, however, that in addition one also needs to have the skills necessary for engaging in the game and carrying out a move. These are the skills to recognize the elements of the game and to manipulate them in the required way. A chess player needs to be able to recognize the pieces and move them on the board, a football player needs to recognize the field and the ball, but also needs to have bodily skills like running, kicking the ball, etc. John Haugeland calls the former constitutive and the latter mundane skills (cf. 1998, 323).

It is important to see that skills come in degree and we are not infallible in their execution. Everyone can occasionally make a mistake and novices will do so more often than

\footnotetext{
${ }^{11}$ According to the descriptivist conception constitutive rules describe the regularities that are manifest in the behaviour of participants in the game. Thus, to describe these regularities, we already need to be able to decide who participates in the practice and who does not.
} 
experienced players. A lucky ignorant might in exceptional circumstances make more correct moves than a willing, yet unexperienced player. A person who does have the relevant knowhow or skill, on the other hand, shows resilience when things occasionally go wrong; she won't give in easily, but try again and manifest a willingness to carry on. ${ }^{12}$ Moreover, a participant has to have a basic form of commitment to the rules that constitute the practice. This commitment is reflected in her readiness to correct moves that are regarded as wrong and the tendency to fine-tune her behaviour to that of the other members of the community. In order to do so, she has to have a (minimal) understanding of being part of a group of individuals who share this commitment - and an ability to recognise who else belongs to it.

The relevance of the criteria for participation can best be seen when we look at the acquisition of one's first language: when infants start to make their first moves in a language game, they cannot be subjects of hypothetical commitments that are contingent on their desire to make correct moves in the game, as the anti-normativists have it, for they cannot possibly consider hypotheticals like the ones mentioned above nor can they have genuine desires. Both would require them to already possess a language. Nonetheless, the caregivers distinguish between correct and incorrect moves and encourage the former - and infants have a natural inclination or propensity to become part of the community in which they grow up. This inclination is not the result of a conscious volition, it is rather an expression of a biological need: as human beings, we are members of a social species. We live in groups not because we choose to do so, but because it is written into our biological constitution, as it were. Moreover, we can do

\footnotetext{
${ }^{12}$ It is notoriously difficult to define resilience. According to John Haugeland's characterization, it "is related to reliability, but is not the same, and maybe a little harder to explain. It's a kind of perseverance born simultaneously of adaptability and self-assurance. I have in mind, as a paradigm of resilience, an expert who 'knows full well' that he or she can do something - and so is not turned aside or discouraged at the first, or even the second, sign of recalcitrance. Adjust a bit here, try that a little longer, don't fall for every semblance of trouble: these are the stuff of resilience as we admire it in physicians and mechanics, scientists and school teachers" (Haugeland 1998, 322).
} 
so only by conforming our behaviour to the regularities that are already manifest in the behaviour of the other (adult) members of the community.

Things might be different for the language student at the beginner's level, who does have a genuine desire to conform her behaviour to the rules that are listed in her textbook. Even if she does observe all the conditional obligations that derive from her textbook, however, she does not use the foreign language to genuinely express herself and interact with others, at least not at the beginner's level. As long as she merely translates from her first language and has to rely on the rules, she will not be regarded as a competent speaker of the foreign language, nor a member of the community. She does not "play the game", as it were. This shows that we regard a person as a competent speaker of Italian (and not "Shmitalian") not because her utterances are in conformity to Italian grammar, but because we accept her to be a member of a (or better: of our ${ }^{13}$ ) social community of speakers, even though we make occasional mistakes.

There are degrees of competence; some persons speak a language badly, but they are still regarded as members of the linguistic community, as it is the case with the infant who makes her first moves in the language game. Others might make only moves that are formally correct, but still not be considered competent speakers, like the language student who has learnt by heart sentences from the textbook. The former genuinely engage in the practice, the latter do not. Similarly, a person plays chess rather than shmess, not because the constitutive rules of chess could be used to describe her behaviour in front of chess-boards, but because others who participate in the social practice recognize that she does intend to play chess, even when she does so badly.

\footnotetext{
${ }^{13}$ The question of whether a person participates in a practice can best be decided from "within", i.e., by other members of the community.
} 
The criteria for participation are admittedly vague. Moreover, it is very difficult to determine from a third-person perspective whether an individual does, in fact, participate in a practice. ${ }^{14}$ There does not seem to be any remedy for this difficulty, though. Participating in a practice is essentially a question of first-person involvement. To gain a more profound understanding of rule-following and commitment to a shared practice, we, thus, have to change perspective and take the first-person into account. This does not entail a turn towards individualism, as "the first person doesn't mean particularly the first-person singular" (Haugeland 1998, 339). As rules are shared practices, we need to consider mainly the first person plural. Only if we take this broader perspective into consideration, we will be able to account for our shared commitment to shared practices.

What is the glue that holds such a community together? Before I can come to address this question, I will briefly discuss the third assumption that characterizes the intellectualist bias in the prevalent conception of constitutive rules.

\section{A Prejudice In Favour Of Sanction}

Many philosophers who discuss the nature of rules see a close relation between rules on the one hand and violations and sanctions, on the other: rules, we often read, can be distinguished from mere regularities by their allowing for errors and violations. The normative force of rules is often explained by the fact that errors and violations, where they occur, stand in need of correction, which can be carried out by the agent herself or called for by an independent authority that is entitled to sanction the agent in case she does not comply. This story seems

\footnotetext{
${ }^{14}$ These difficulties surface in the philosophical debates concerning other minds or strong artificial intelligence.
} 
particularly suited for codified systems of rules. In fact, most laws - and in particular the most basic laws, such as the constitution - but also some rulebooks explicitly devolve authority to an individual or a group of individuals to monitor the behaviour of others and sanction their violations. Typically, the police or a referee fulfils this function. The focus on violation and sanction is likely due to the fact that in these moments rules become most likely noted. Both a good player of a game and a competent speaker of a language - just like a person who drives her car and likes to speed up - have interiorized the rules that govern their behaviour and do not normally become aware of them in their everyday routine. When they are corrected for a mistake and have to take a fine, they become painfully aware of the rule and its restrictive character.

If you carry this conception of rules over to language, the normativist position can easily appear overly restrictive and hierarchical, which could have motivated the formulation of the anti-normativist position in the first place. ${ }^{15}$ But this might be only an overreaction caused by the threat of an overly regulistic conception of grammar. The reaction points in the right direction; in fact, the conception of rules that I have sketched above, and which relies on the notion of sanction, does not do justice to the nature of grammar. But it goes too far.

Natural languages are very complex systems that are dynamic and are subject to constant change and development. Every rule that was or could be formulated by grammarians allows for plenty of exceptions and variations in different regions or social contexts. The normative force of the rules of grammar cannot, thus, come from an authority that proclaims prescriptions or monitors their correct application. In fact, like most of our social practices, also language does not know a sanctioning authority. Contrary to all Karl Krausian phantasies

\footnotetext{
${ }^{15}$ Anti-normativists often represent the normativist conception as holding that our linguistic behaviour is guided by "prescriptions" (cf. Glonc and Pagin 1998; Wikforss 2001; Hattiangadi 2006) - and add that "[p]aradigm examples of prescriptions are the laws of state" (Glxam and Pagin 1998, 215).
} 
we might indulge in when coming across awkward neologisms or other forms of violence against language, there is no "language police". Language is a game we play together with the other members of our linguistic community - and we play it without a referee. All competent speakers are at the same level (though some might feel more confident than others); any competent speaker has to be able to detect (and point out to others) errors or violations.

The rules of grammar (as formulated by grammarians), thus, are "signposts" that guide, but do not prescribe in a detailed manner, our linguistic behaviour. They are particularly helpful for non-native speakers or for experts who have occasional doubts. The very fact that native speakers, who have no trouble to conform (by and large) to the rules and observe the exceptions, very often are not familiar with the rules while non-native speakers, who often know the rules by heart, have difficulties in applying them ${ }^{16}$ shows that we need to amend our conception of rules when we want to get a more profound understanding of the normativity of language. This conception will have to take into account that language - like most other social practices - is a shared activity in which one can engage only together with others and which, in turn, presupposes a shared commitment.

\section{Calibrating One's Behaviour To That Of Others}

This aspect becomes most evident when we think of examples where friction undermines the harmony among the players. Take a member of a linguistic community who, at some point, starts to deviate systematically and in substantial respects from the linguistic behaviour of the other members of the community. If the deviations are only local, communication will still be

\footnotetext{
${ }^{16}$ I discuss these points in more detail in Huemer (2020).
} 
possible. The person's new way of speaking might pass as mannerism, idiosyncrasy, or a form of language impairment. If she is a person of public interest, her idiosyncratic way of speaking might catch on in a larger part of the community, and persons who adopt this way of speaking might feel to belong to the same group or clique. Eventually, it might even become the new rule.

If, on the other hand, the individual's deviations are too substantial, linguistic interaction with the other members of the community will break down. At this point, she might just give in and keep silent - or show resilience and make an attempt to re-establish a shared commitment with others. If, for some reason or other, she cannot (or does not want to) return to her old patterns of behaviour - she might be paralyzed after an accident and only be able to move her eyes - she might try to establish new ones on a different ground and try to convince others to follow her lead. This will be possible only if the others are still regarding her as a member of their community (or for some other reasons want to engage in a shared practice with her) and are willing to make the effort to acquire the new skills that are necessary for engaging in linguistic interaction with her.

Note that in the present example, this process does not (need to) take place at a linguistic level but can take the form of a pre-linguistic or non-linguistic understanding. When encountering other members of our species we are typically quite good in reading their reactions to our shared environment, even if we do not speak a shared language. ${ }^{17}$ On the basis of this nonlinguistic understanding she can share her (new) commitments with us - and we can take up and interiorize the regularities in the pattern of behaviour. We calibrate, on a non-verbal level, our own behaviour to hers and so come to share her commitment. "I do it, he does it after me;

\footnotetext{
${ }^{17}$ This was pointed out already by Wittgenstein: "Think of the behaviour characteristic of someone correcting a slip of the tongue. It would be possible to recognise that someone was doing so even without knowing his language" (Wittgenstein 2009, 31, §54).
} 
and I influence him by expressions of agreement, rejection, expectation, encouragement. I let him go his way, or hold him back; and so on" (Wittgenstein 2009, 89, §208). In this way, a new practice comes into existence; the glue that holds it together is the propensity of all participants who actively engage in it to continuously calibrate their own behaviour to that of the others.

This example suggests that the basic elements that guarantee the inner cohesion and the persistence over time of our social practices and the community of individuals who engage in it are not sets of constitutive rules - at least not if we conceive them as rules that can always be explicitly formulated and have a logical form. The basic elements are rather enacted rules and a shared commitment - which contains a commitment to belong to the group. Even though the rules might never be spelled out explicitly, the individuals who engage in the practice have both the skills to apply them in appropriate situations and the skills to distinguish correct from incorrect moves and point errors out to others.

Rules, however - be they explicit or not - cannot guarantee for every future application. As Wittgenstein $(2009,91, \S 218)$ has pointed out, rules are not like rails that are extended to infinity and do not leave any leeway. Rather, they are like guidelines that recommend certain forms of behaviour, but will have to be interpreted, adapted, or even modified in ever new circumstances of application that cannot possibly have been foreseen by the legislator or the authors of the rulebook.

This conception of rule-following can take the dynamics of language into account and explain why it continually undergoes changes that are unpredictable by linguists. It also shows that language is always in a precarious equilibrium ${ }^{18}$ that can remain stable only if all (or at least

\footnotetext{
18 This point was argued by Di Paolo, Cuffari, and De Jaegher (2018) who focus on linguistic interactions in dialogical situations and small communities. Systems of rules like that of grammar become probably more important when we think of more stable equilibria - like the ones we have in articulate languages that are spoken in large linguistic communities - where the regularities in the patterns that have emerged must have sedimented.
} 
most) members of the community adapt their own commitments along roughly the same lines. A shared commitment presupposes, thus, that members of a community continuously react to changes in the patterns of the behaviour of their peers and adapt their own behaviour to these changes. A social practice can exist over time only if the individuals that engage in it continuously calibrate their own behaviour to that of the others.

This process of calibration can take place at different levels of complexity. The phenomena that I have focused on in the preceding pages can be understood as a symptom of a tacit form of conformism, an unconscious inclination to follow the examples of the others, which might be rooted in our biological constitution. These are the mechanisms that make social practices possible in the first place and contribute to their inner cohesion and to their persistence over time (notwithstanding the constant changes to which they are subjected). ${ }^{19}$ Calibration can also take place at a more complex level that entails discussions about the linguistic norms that guide our practice. In a series of papers, Matthias Kiesselbach $(2012 ; 2014 ; 2020)$ has drawn attention to the fact that language contains a practice of calibration or a "calibration game", as he calls it, that allows participants to render their own commitments (or that of others) explicit. A calibration game of this kind is part of a more comprehensive shared practice, typically that of an articulate language that allows for discussions over the use of certain terms. It seems best suited for local deviations where participants still have the possibility to discuss their disagreement and weigh the reasons for their deviating views with the others, who are still members of the same linguistic community.

What seems most relevant to me is that at all levels of complexity, the inclination of calibrating one's behaviour to that of the other members of the community unveils a most important aspect: human beings are social animals that look out for the interaction with others

\footnotetext{
${ }^{19}$ I develop this claim in more detail in Huemer (2020).
} 
and are willing to conform their own behaviour to the regularities that emerge from the behaviour of the other members of their community. This is the glue that holds our community together over time. We are conformist creatures who have a natural propensity to engage in social practices that are based on a commitment that is shared with others. It is, thus, shared commitment that confers a normative status to the patterns of behaviour that emerge from the practice. ${ }^{20}$

\section{References}

Bicchieri, Cristina. 2006. The Grammar of Society: The Nature and Dynamics of Social Norms. New York: Cambridge University Press. 2017. Norms in the Wild: How to Diagnose, Measure, and Change Social Norms. New York, NY: Oxford University Press.

Brandom, Robert B. 1998. Making It Explicit: Reasoning, Representing, and Discursive Commitment. Cambridge, Mass.: Harvard University Press.

Di Paolo, Ezequiel A., Elena Clare Cuffari, and Hanne De Jaegher. 2018. Linguistic Bodies: The Continuity between Life and Language. Cambridge, Massachusetts: The MIT Press.

Glock, Hans-Johann. 2000. 'Wie kam die Bedeutung zur Regel?' Deutsche Zeitschrift für Philosophie 48 (3): 429-47.

Glüer, Kathrin, and Peter Pagin. 1998. 'Rules of Meaning and Practical Reasoning'. Synthese

\footnotetext{
${ }^{20}$ I want to express my thanks to Matthias Kiesselbach for detailed critique and helpful suggestions as well as for the comments I received when presenting earlier versions of the paper at a Cogito Seminar in Bologna, at the Philosophisches Kolloquium of the University of Erfurt and at the workshop "The Social Construction of Norms" at the University of Vienna.
} 
117 (2): 207-27. https://doi.org/10.1023/A:1005162503125.

Hattiangadi, Anandi. 2006. 'Is Meaning Normative?' Mind \& Language 21 (2): 220-40. https://doi.org/10.1111/j.0268-1064.2006.00312.x.

Haugeland, John. 1998. 'Truth and Rule-Following'. In Having Thought: Essays in the Metaphysics of Mind, 305-61. Cambridge, Mass: Harvard University Press.

Hindriks, Frank. 2009. 'Constitutive Rules, Language, and Ontology’. Erkenntnis 71 (2): 253-75. https://doi.org/10.1007/s10670-009-9178-6.

Huemer, Wolfgang. 2020. 'Rule-Governed Practices in the Natural World'. Journal of Transcendental Philosophy 1 (1): 161-81. https://doi.org/10.1515/jtph-2019-0016.

Kiesselbach, Matthias. 2012. 'Constructing Commitment: Brandom's Pragmatist Take on Rule-Following: Philosophical Investigations'. Philosophical Investigations 35 (2): 101-26. https://doi.org/10.1111/j.1467-9205.2011.01450.x.

. 2014. 'The Normativity of Meaning: From Constitutive Norms to Prescriptions'. Acta Analytica 29 (4): 427-40. https://doi.org/10.1007/s12136-014-0221-0.

2020. 'On Being Bound to Linguistic Norms. Reply to Reinikainen and Kaluziński'. International Journal of Philosophical Studies, 1-14. https://doi.org/10.1080/09672559.2020.1782561.

Peregrin, Jaroslav. 2014. Inferentialism: Why Rules Matter. New York: Palgrave Macmillan.

Ransdell, Joseph. 1971. 'Constitutive Rules and Speech-Act Analysis'. The Journal of Philosophy 68 (13): 385-400. https://doi.org/10.2307/2025037.

Rawls, John. 1955. 'Two Concepts of Rules'. The Philosophical Review 64 (1): 3-32. https://doi.org/10.2307/2182230. 
Rüegg, Walter. 2003. 'Themes'. In A History of the University in Europe: Volume 1, Universities in the Middle Ages, edited by Hilde de Ridder-Symoens and Walter Rüegg, 3-34. A History of the University in Europe. Cambridge University Press. https://books.google.de/books?id=5Z1VBEbF0HAC.

Searle, John R. 1969. Speech Acts: An Essay in the Philosophy of Language. Cambridge: Cambridge University Press.

-1995. The Construction of Social Reality. New York: Free Press.

Sellars, Wilfrid. 1991. 'Some Reflections on Language Games'. In Science, Perception and Reality, 321-58. Atascadero, Calif.: Ridgeview Pub.

Wikforss, Åsa Maria. 2001. ‘Semantic Normativity'. Philosophical Studies 102 (2): 203-26. https://doi.org/10.1023/A:1004746319850.

Wittgenstein, Ludwig. 2009. Philosophical Investigations. Edited by P. M. S. Hacker and Joachim Schulte. Translated by G.E.M. Anscombe, P. M. S. Hacker, and Joachim Schulte. Rev. 4th ed. Malden, MA: Blackwell. 